\title{
Prevalence of Valproate Syndrome in Europe from 2005 to 2014 : \\ a registry based multi-centre study
}

Professor Joan K Morris ${ }^{1}$, Dr Ester Garne ${ }^{2}$,Dr Maria Loane ${ }^{3}$, Dr Marie-Claude Addor ${ }^{4}$, Prof Ingeborg Barisic $^{5}$, Dr Fabrizio Bianchi ${ }^{6}$, Dr Miriam Gatt ${ }^{7}$, Dr Monica Lanzoni ${ }^{8}$, Dr Catherine Lynch ${ }^{9}$, Ms Olatz Mokoroa ${ }^{10}$, Dr Vera Nelen ${ }^{11}$, Dr Amanda Neville ${ }^{12}$, Dr Mary T. O'Mahony ${ }^{13}$, Dr Hanitra RandrianaivoRanjatoelina ${ }^{14}$, Dr Anke Rissmann ${ }^{15}$, Mr David Tucker ${ }^{16}$, Dr H.E.K. de Walle ${ }^{17}$, Dr Nataliia ZymakZakutnia $^{18}$, Professor Judith Rankin ${ }^{19}$

1. Wolfson Institute of Preventive Medicine Queen Mary University of London, UK

2. Paediatric Department, Hospital Lillebaelt, Kolding, Denmark

3. Ulster University, UK

4. Service de Médecine Génétique, CHUV Lausanne, Switzerland

5. Chlidren's Hospital Zagreb, Croatia

6. Institute of Clinical Physiology-National Research Council (IFC-CNR), Pisa, Italy;

7. Malta Congenital Anomalies Registry, Directorate for Health Information and Research, Malta

8. European Commission, DG Joint Research Centre, Directorate F - Health, Consumers and Reference Materials. Ispra, Italy

9. HSE SE, Kilkenny, Ireland

10. Public Health Division of Gipuzkoa, Biodonostia Research Institute, Donostia-San Sebastian, Spain

11. PIH, Province of Antwerp, Department of Environment, Antwerp, Belgium

12. Center for Clinical and Epidemiological Research, University of Ferrara, Italy

13. HSE South (Cork \& Kerry), Ireland

14. Chu Sud Reunion,St Pierre, Ile de la Reunion

15. Malformation Monitoring Centre Saxony-Anhalt, Medical Faculty Otto-von-Guericke University Magdeburg, Germany

16. Public Health Wales NHS Trust, UK

17. University of Groningen, the Netherlands.

18. OMNI-Net Ukraine Birth Defects Program and Khmelnytsky City Children's Hospital, Ukraine 19. Institute of Health \& Society, Newcastle University, UK

Running Title : Valproate syndrome in Europe

\section{Corresponding Author :}




\section{Professor J K Morris}

Centre for Environmental and Preventive Medicine, Wolfson Institute of Preventive Medicine,

Barts and the London School of Medicine and Dentistry,

Queen Mary University of London,

Charterhouse Square,

London EC1M 6BQ

Email : j.k.morris@qmul.ac.uk

Tel : 02078826274

Fax: 02078826269

Conflict of interest. The authors declare no conflict of interest 
Abstract

Women with epilepsy need to continue to take anti-convulsants during their pregnancies to prevent seizures from occurring. Since the 1980's, it has been known that the use of valproate (an anticonvulsant) in the first trimester of pregnancy is associated with an increased risk of spina bifida. Recent studies have also demonstrated increased risks of other congenital anomalies as well as a risk of cognitive impairment. Doctors in the EU are now advised not to prescribe valproate in pregnant women, in women who can become pregnant or in girls unless other treatments are ineffective or not tolerated. This study aimed to determine if there has been a reduction in the numbers of babies born with valproate syndrome in Europe from 2005 to 2014. Data from 15 European congenital anomaly registries, who are members of EUROCAT (A European network of population-based registries for the epidemiologic surveillance of congenital anomalies), identified 28 cases of valproate syndrome in 2.74 million births from 2005 to 2014 . The prevalence of valproate syndrome in Europe significantly decreased from 0.22 per 10,000 births in $2005 / 6$ to 0.03 per 10,000 births in $2013 / 14$. One registry, Ille de la Reunion, had the majority of cases (17). After excluding these cases there still remained a decreasing trend even though it no longer reached statistical significance due to the small number of cases. This study emphasises the continued need for European collaboration in analysing rare exposures and rare anomalies.

Keywords : Sodium valproate, valproic acid, congenital anomaly 


\section{Introduction}

Epilepsy effects about $0.5 \%$ of women of child-bearing age (Wallace et al., 1998). It is necessary for these women to take anti-convulsants in order to prevent seizures from occurring, particularly during pregnancy when the seizures can be harmful to the women and also the fetus (Charlton et al., 2015; Tomson et al., 2016). However, first trimester exposure to anticonvulsants has been shown to increase the risk of congenital anomalies-, particularly neural tube defects, occurring in the fetus (Dravet et al., 1992; Kaneko et al., 1999; Samren et al., 1997). Valproate has been identified as being more teratogenic than many other anti=epileptic medications, increasing the risk of spina bifida and other congenital anomalies including atrial septal defect, cleft palate, hypospadias, polydactyly and craniosynostosis (Jackson et al., 2016; Jentink et al., 2010b; Tomson et al., 2015). The term fetal valproate syndrome was first described in 1984 (DiLiberti et al., 1984) and includes facial dysmorphism, congenital anomalies and neurodevelopmental problems. Prospective studies have also identified an increased risk of cognitive function and neuro-developmental problems in children with in-utero exposure to valproate (Bromley et al., 2014; Cummings et al., 2011; Wood et al., 2015). Advice to pregnant women to avoid taking valproate was first considered in 1984 (DiLiberti et al., 1984) and the warnings have been consistently strengthened with the National Institute for Clinical Excellence (NICE) Clinical Guidelines in 2012 recommending that women and girls of childbearing potential should be informed of the risks of malformation in an unborn child (2012). The Pharmacovigilance Risk Assessment Committee (PRAC) of the European Medicines Agency in 2018 recommended new measures to avoid valproate exposure in pregnancy. However, if treatment with valproate has been providing good seizure control, women may be reluctant to change to another less efficient medication before or during pregnancy (Tomson et al., 2016). In addition other antiepileptics, such as Carbamazapine, are also teratogenic (Jentink et al., 2010a) and although the newer generation of anti=epileptics (such as lamotrigine and levetiracetam) appear safer there is limited information on-their effect on the developing fetusthem. As many pregnancies are also unplanned, it may be difficult to completely prevent fetal exposure to valproate, particularly in the first trimester.

European surveillance of congenital anomalies (EUROCAT) is a European network of populationbased registries for the epidemiologic surveillance of congenital anomalies-(EUROCAT, http://www.eurocat-network.eu/). It surveys all pregnancy outcomes from high-quality multiplesource registries in Europe (Dolk, 2005). Annual statistical monitoring for five and 10 year trends in 94 non-independent congenital anomaly groups is performed to detect any changes in prevalence. 
The aim of this report is to determine if the prevalence of valproate syndrome has decreased in 15 EUROCAT registries from 2005 to 2014.

\section{Subjects and-Methods \\ Data sources}

Data in this study were obtained from EUROCAT registries that use multiple sources of information to ascertain cases in live births, late fetal deaths (20+ weeks' gestation), and terminations of pregnancy for fetal anomaly at any gestation. Sources, depending on the registry, include maternity, neonatal, and paediatric records; fetal medicine, cytogenetic, pathology, and medical genetics records; specialist services including paediatric cardiology; and hospital discharge and child health records. The majority of registries ascertain cases diagnosed up to at least one year of life, with some registries having no upper age limit for registration. All cases are coded to the International Classification of Diseases (ICD) version 10 with 1-digit British Paediatric Association (BPA) extension. Cases can have up to nine syndrome or malformation codes. All coding is completed using the EUROCAT guide 1.4 .

Aggregate Data were extracted from the Joint Research Council (-JRC)-EUROCAT Central database in October 2016. The Central Database is managed by the JRC-EUROCAT Central Registry which operates the European level-coordination activities of the EUROCAT Network as part of the European platform on Rare Diseases Registration. The JRC-EUROCAT Central Registry is located at the European Commission Joint Research Centre in Ispra, Italy.

Fifteen rRegistries that had submitted data to EUROCAT for at least nine of the ten years from 2005 to 2014 (during the study period) were included in the analysis. Cases of valproate syndrome were those with an ICD/BPA 10 code Q8680 (congenital malformations due to valproate), with registries requiring a confirmation of diagnosis by a clinical geneticist or paediatrician, rather than just a record of the mother having taken valproate. The present analysis was performed in the framework of the routine calculation of the EUROCAT prevalence tables for surveillance, using aggregated data and therefore the written text descriptions of the anomalies were not available.

\section{Statistical Analysis}

The ten-year trend in prevalence was examined by fitting a multi-level Poisson regression model on the number of cases of the anomaly in each two year period within each registry, with the total 


\begin{tabular}{lccc}
\hline Registry & $\begin{array}{c}\text { Number of } \\
\text { Pregnancies }\end{array}$ & $\begin{array}{c}\text { Number of cases of } \\
\text { valproate syndrome }\end{array}$ & $\begin{array}{c}\text { Prevalence per 10,000 } \\
\text { births }(95 \% \mathrm{Cl})\end{array}$ \\
\hline Tuscany, Italy & 299,869 & 0 & $0.00(0.00-0.12)$ \\
North Netherlands & 173,671 & 3 & $0.17(0.04-0.50)$ \\
Emilia Romagna, Italy & 400,208 & 1 & $0.03(0.01-0.14)$ \\
Vaud, Switzerland & 79,037 & 1 & $0.13(0.00-0.70)$ \\
Zagreb, Croatiat & 66,163 & 0 & $0.00(0.00-0.56)$ \\
Maltat & 36,820 & 0 & $0.00(0.00-1.00)$ \\
South Portugal & 181,903 & 0 & $0.00(0.00-0.20)$ \\
Antwerp, Belgium & 184,955 & 1 & $0.05(0.00-0.30)$ \\
Basque Country, Spain $\underline{ \pm}$ & 185,352 & 1 & $0.05(0.00-0.30)$ \\
Saxony Anhalt, Germany & 171,877 & 2 & $0.12(0.01-0.42)$ \\
Cork and Kerry, Ireland $\underline{\underline{y}}$ & 89,379 & 0 & $0.00(0.00-0.41)$ \\
Wales, UK & 347,032 & 1 & $0.03(0.00-0.16)$ \\
Ukraine & 303,935 & 0 & $0.00(0.00-0.12)$ \\
Isle de la Reunion, France & 145,764 & 17 & $1.17(0.68-1.87)$ \\
South East Ireland & 74,527 & 1 & $0.13(0.00-0.75)$
\end{tabular}

number of births occurring in the area covered by the registry as the exposure. Random-effects models were used in order to account for potential heterogeneity across registries. A second multilevel Poisson model was fitted combining each two years of data and entering them as a categorical variable to provide estimates (and 95\% confidence intervals $(\mathrm{CI})$ ) of the prevalence for each two year period adjusted for the registries as some registries did not have data for the whole of the study time period. All analyses were performed using Stata version 12.

\section{Results}

Table 1 shows that 28 cases with valproate syndrome were reported in 2.74 million births from 2005 to 2014. One registry, Ille de la Reunion, had the majority of cases (17 out of 28).Figure 1 shows that the prevalence of valproate syndrome in Europe has significantly decreased over the past ten years ( $p<0.001)$ from 0.22 per 10,000 births in $2005 / 6$ (95\% Cl: 0.11 to 0.39$)$ to 0.043 per 10,000 births in 2013/14 (95\% Cl:0.005 to 0.15). After excluding the cases from Ille de la Reunion there still remained a decreasing trend (grey lines on figure 1) even though it no longer reached statistical significance due to the small number of cases. 


\begin{tabular}{llll}
\hline Total & $2,740,492$ & 28 & $0.10(0.07-0.15)$
\end{tabular}

$t$ : These registries only submitted data for nine years.

\section{Table 1 : Number of cases of valproate syndrome and prevalence per 10,000 births in EUROCAT} registries 2005-2014.

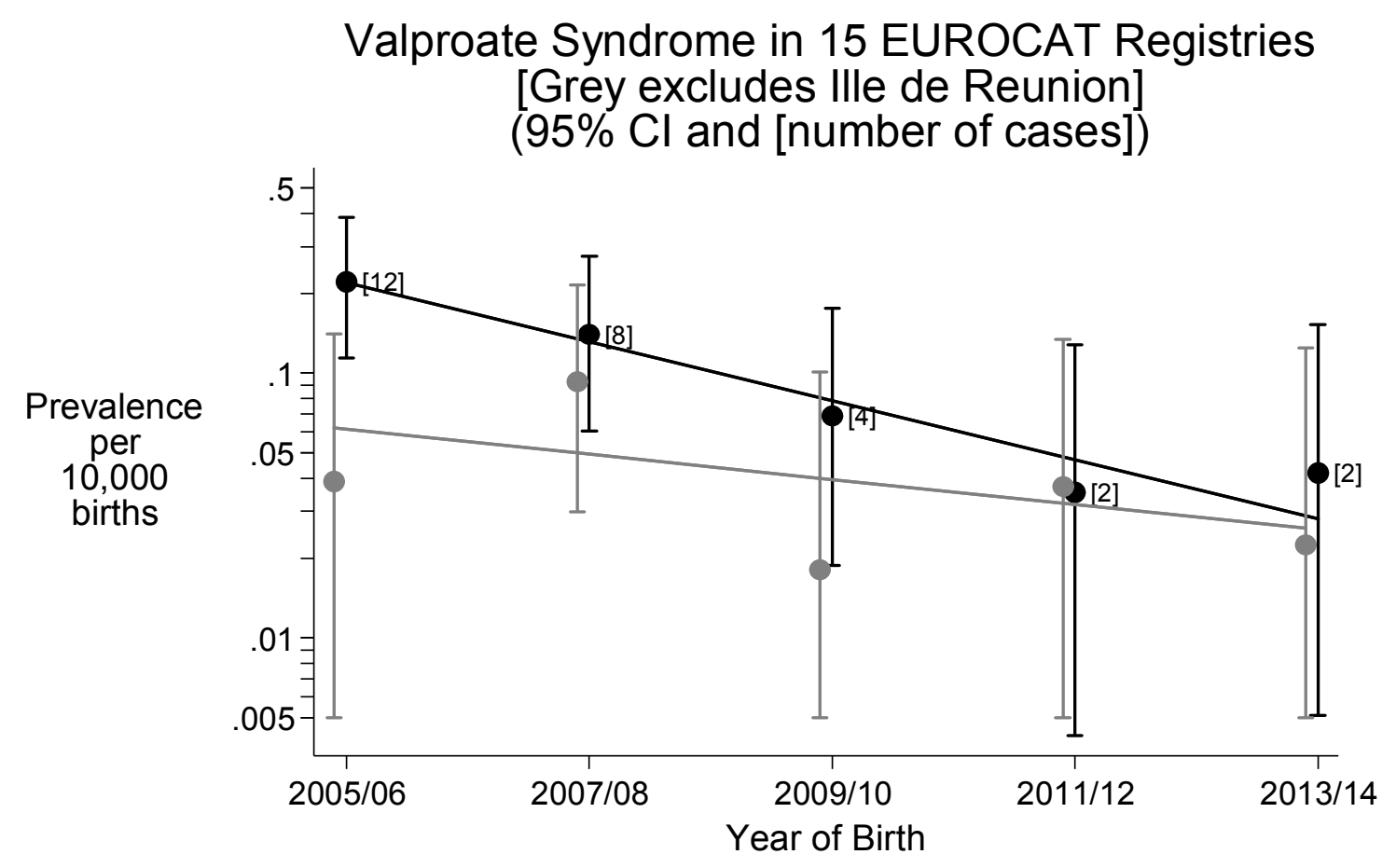


Figure 1 : Prevalence of valproate syndrome (with $95 \% \mathrm{Cl}$ and [number of cases]) in 15 EUROCAT registries, 2005-2014 in EUROCAT registries

Figure footnote: Grey excludes cases from lle de la Reunion.

\section{Discussion}

There were 28 cases with valproate syndrome notified to 15 European congenital anomaly registries, an average of less than two cases per registry over the ten year period. This is too few within each registry to detect any changes in prevalence. However, combining these data across 15 registries enabled the clear decreasing trend to be observed. The majority of cases occurred in lle de la Reunion, probably reflecting the higher prescription rates there. However a decreasing trend (although not significant) did remain once the cases from lle de la Reunion were excluded. EUROCAT surveillance of trends across all anomaly groups is performed annually and tThis is the third year that the decrease in valproate syndrome has been identified in the annual EUROCAT surveillance. With the increasing focus on valproate syndrome in recent years (Bromley et al., 2014; Cummings et al., 2011; Jackson et al., 2016; Jentink et al., 2010b; Tomson et al., 2015; Wood et al., 2015), it is reasonable to assume that under-ascertainment is not a likely explanation for the observed decrease. In addition an analysis of prescription databases in 7 European countries from 2004-2010 observed a decrease in the prescription of valproate in pregnancy in all countries except for Italy 
(Charlton et al., 2015). A change in prescribing practice is thought to be a more likely explanation. A fall in prescribing valproate has also been observed in Ireland from 2008 to 2013 (Murphy et al., 2016) and in the UK in girls from 1993 to 2006 (Ackers et al., 2009). It is important to reduce valproate usage in women before they become pregnant as it has been shown that switching medications during pregnancy carries a risk of seizures occurring (Tomson et al., 2016). In the most recent guideline from the EMA it is recommended not to prescribe valproate to women who can become pregnant or in any girls.(EMA, 2014)

A weakness-limitation of the study is that the diagnosis of valproate syndrome may differ between registries, although EUROCAT has standard definitions for coding of congenital anomalies. A further limitation is that only three registries are contributing the majority of cases. However a strength of this study is that it is a multi-centre collaborative study using high-quality registry data coded over many years in a consistent manner using the EUROCAT classification codes and inclusion criteria. The quality of this data enables the monitoring of trends in such rare and potentially preventable conditions. This study includes all registries contributing data to the surveillance of all congenital anomalies in October 2016.

This study emphasises the continued need for multi-centre European collaboration in analysing monitoring rare congenital anomalies arising from exposure to teratogenic drugsrare exposures and fare anomalies.

\section{Acknowledgements}

We thank the many people throughout Europe involved in providing and processing information, including affected families, clinicians, health professionals, medical record clerks, and registry staff.

\section{Funding}

EUROCAT registries are funded as fully described in Paper 6 of Report 9 - EUROCAT Member Registries: Organization and Activities. The responsibility for the interpretation of data and/or information supplied is the authors' alone.

\section{References}

EUROCAT Guide 1.4.hH:D://W network.eu/aboutus/datacollection/guidelinesforregistration/guide1 4. (Accessed 14/02/2018. Ackers, R., Besag, F.M., Wade, A., Murray, M.L., Wong, I.C., 2009. Changing trends in antiepileptic drug prescribing in girls of child-bearing potential. Arch Dis Child 94(6), 443-447. 
Bromley, R., Weston, J., Adab, N., Greenhalgh, J., Sanniti, A., McKay, A.J., Tudur Smith, C., Marson, A.G., 2014. Treatment for epilepsy in pregnancy: neurodevelopmental outcomes in the child. The Cochrane database of systematic reviews(10), Cd010236.

Charlton, R., Garne, E., Wang, H., Klungsoyr, K., Jordan, S., Neville, A., Pierini, A., Hansen, A., Engeland, A., Gini, R., Thayer, D., Bos, J., Puccini, A., Nybo Andersen, A.M., Dolk, H., de Jong-van den Berg, L., 2015. Antiepileptic drug prescribing before, during and after pregnancy: a study in seven European regions. Pharmacoepidemiology and drug safety 24(11), 1144-1154.

Cummings, C., Stewart, M., Stevenson, M., Morrow, J., Nelson, J., 2011. Neurodevelopment of children exposed in utero to lamotrigine, sodium valproate and carbamazepine. Arch Dis Child 96(7), 643-647.

DiLiberti, J.H., Farndon, P.A., Dennis, N.R., Curry, C.J., 1984. The fetal valproate syndrome. American journal of medical genetics 19(3), 473-481.

Dolk, H., 2005. EUROCAT: 25 years of European surveillance of congenital anomalies. Arch Dis Child Fetal Neonatal Ed 90(5), F355-358.

Dravet, C., Julian, C., Legras, C., Magaudda, A., Guerrini, R., Genton, P., Soulayrol, S., Giraud, N., Mesdjian, E., Trentin, G., et al., 1992. Epilepsy, antiepileptic drugs, and malformations in children of women with epilepsy: a French prospective cohort study. Neurology 42(4 Suppl 5), 75-82.

EMA, 2014. PRAC recommendations.

http://www.ema.europa.eu/ema/index.jsp?curl=pages/news_and_events/news/2018/02/news_det ail_002903.jsp\&mid=WC0b01ac058004d5c1. . (Accessed 12/02/2018.

EUROCAT Guide 1.4. http://www.eurocatnetwork.eu/aboutus/datacollection/guidelinesforregistration/guide1_4. (Accessed 14/02/2018.

Jackson, A., Bromley, R., Morrow, J., Irwin, B., Clayton-Smith, J., 2016. In utero exposure to valproate increases the risk of isolated cleft palate. Arch Dis Child Fetal Neonatal Ed 101(3), F207-211.

Jentink, J., Dolk, H., Loane, M.A., Morris, J.K., Wellesley, D., Garne, E., de Jong-van den Berg, L., Group, E.A.S.W., 2010a. Intrauterine exposure to carbamazepine and specific congenital malformations: systematic review and case-control study. BMJ 341, c6581.

Jentink, J., Loane, M.A., Dolk, H., Barisic, I., Garne, E., Morris, J.K., de Jong-van den Berg, L.T., 2010b. Valproic acid monotherapy in pregnancy and major congenital malformations. N Engl J Med 362(23), 2185-2193.

Kaneko, S., Battino, D., Andermann, E., Wada, K., Kan, R., Takeda, A., Nakane, Y., Ogawa, Y., Avanzini, G., Fumarola, C., Granata, T., Molteni, F., Pardi, G., Minotti, L., Canger, R., Dansky, L., Oguni, M., Lopes-Cendas, I., Sherwin, A., Andermann, F., Seni, M.H., Okada, M., Teranishi, T., 1999. Congenital malformations due to antiepileptic drugs. Epilepsy research 33(2-3), 145-158.

Murphy, S., Bennett, K., Doherty, C.P., 2016. Prescribing trends for sodium valproate in Ireland. Seizure 36, 44-48.

NICE, 2012. The epilepsies: the diagnosis and management of the epilepsies in adults and children in primary and secondary care. http://www.nice.org.uk/nicemedia/pdf/CG020NICEguideline.pdf

Samren, E.B., van Duijn, C.M., Koch, S., Hiilesmaa, V.K., Klepel, H., Bardy, A.H., Mannagetta, G.B., Deichl, A.W., Gaily, E., Granstrom, M.L., Meinardi, H., Grobbee, D.E., Hofman, A., Janz, D., Lindhout, D., 1997. Maternal use of antiepileptic drugs and the risk of major congenital malformations: a joint European prospective study of human teratogenesis associated with maternal epilepsy. Epilepsia 38(9), 981-990. 
Tomson, T., Battino, D., Bonizzoni, E., Craig, J., Lindhout, D., Perucca, E., Sabers, A., Thomas, S.V., Vajda, F., 2015. Dose-dependent teratogenicity of valproate in mono- and polytherapy: an observational study. Neurology 85(10), 866-872.

Tomson, T., Battino, D., Bonizzoni, E., Craig, J., Lindhout, D., Perucca, E., Sabers, A., Thomas, S.V., Vajda, F., the, E.S.G., 2016. Withdrawal of valproic acid treatment during pregnancy and seizure outcome: Observations from EURAP. Epilepsia 57(8), e173-e177.

Wallace, H., Shorvon, S., Tallis, R.,1998. Age-specific incidence and prevalence rates of treated epilepsy in an unselected population of $2 \& \# \times 2008 ; 052 \& \# \times 2008 ; \div 922$ and age-specific fertility rates of women with epilepsy. The Lancet 352(9145), 1970-1973.

Wood, A.G., Nadebaum, C., Anderson, V., Reutens, D., Barton, S., O'Brien, T.J., Vajda, F., 2015.

Prospective assessment of autism traits in children exposed to antiepileptic drugs during pregnancy. Epilepsia 56(7), 1047-1055. 